\title{
3D SURVEY TECHNIQUES FOR THE ARCHITECTUTAL RESTORATION: THE CASE OF ST. AGATA IN PISA
}

\author{
M.G. Bevilacqua ${ }^{\mathrm{a}}$, G. Caroti ${ }^{\mathrm{b}, *}$, A. Piemonte ${ }^{\mathrm{b}}$, P. Ruschi ${ }^{\mathrm{a}}$, L. Tenchini $^{\mathrm{a}}$ \\ a DESTEC, University of Pisa,mg.bevilacqua@ing.unipi.it, pietro.ruschi@ing.unipi.it, lavinia_tench@yahoo.com \\ b DICI, University of Pisa, gabriella.caroti@unipi.it, andrea.piemonte@unipi.it
}

\author{
Commission V, WG V/1, WG V/2 \\ Commission II, WG II/8 \\ CIPA
}

KEY WORDS: architectural survey, laser scanning, Structure from Motion, restoration, Pisa, St. Agata

\begin{abstract}
:
The historical architectural heritage may be considered as the product of a complex system of interaction between several factors cultural, socio-economic, technical, aesthetic etc. The restoration and conservation of this important heritage, therefore, requires necessarily a multidisciplinary approach, both in the preliminary phase of knowledge and in the operative one, strictly connected to the first, regarding the development of the restoration works in all their steps, from the project to the realization.

The historical-critical analysis of bibliographic, archival and iconographic sources, together with the architectural survey, aims at interpreting all the events that, from the initial project to all the eventual phases of transformation, have lead the monument in its current state. This is therefore a multi-temporal and multi-spatial study in which geomatics gives an innovative contribution for its capability of gathering, storing, processing, and delivering different levels of spatially referenced information.

The current techniques of architectural survey, supported by specific methodological skills, are therefore not limited to a mere mathematical-geometrical description of the historical building, but are useful also for many other purposes, such as formal-linguistic analysis, interpretation of the historical phases of transformation, description of the state of degradation/conservation etc. In this interdisciplinary perspective, photogrammetry and laser scanner represent the two main techniques, as they offer the greatest potential of performing integrated surveys.

In the last decades, we have witnessed the growth and development of these 3D-survey techniques as alternative or complementary tools to the traditional ones. In particular, in the field of architectural restoration, these techniques have made significant improvements not only in terms of measure precision or reduction of time for survey operations, but also for the possibility to represent and visualize the historical building in its context. These modern techniques of survey, based on the creation of point clouds, are now widely used both in the study of a building and for the thorough description of architectural details and decorations.

This paper aims at describing the methodological approach and the results of the 3D survey of the Chapel of St. Agata in Pisa, aimed at its restoration.

For the development of a restoration project, the survey drawings must represent not only the geometry of a building, but also the materials and the level of degradation. So, we chose to use both the laser scanner - which guarantees uniformity of the geometric survey precision - and a 3D image-based modelling. The combined use of these two techniques, supported by a total station survey, has produced two point clouds in the same reference system, and allowed the determination of the external orientation parameters of the photographic images. Since these parameters are known, it was possible to texturize the laser scanner model with high quality images. The adopted methodology, as expected, gave back metrically correct and graphically high-quality drawings. The level of detail of the survey, and consequently of the final drawings, has been previously defined for the identification of all the elements required for the analysis of the current state, such as the clear identification and position of all the degradation phenomena, materials and decorative elements such as some fragmented and heavily damaged frescoes.
\end{abstract}

\section{INTRODUCTION}

In the past years, the field of preservation and development of cultural, architectural and archaeological heritage has benefited from an ever increasing use of new surveying methodologies (Tucci et al., 2015; Fregonese et al., 2016; Lo Brutto et al., 2011). Several advantages are in fact provided (Costantino et al., 2016; D'Urso et al., 2014; Dominici et al.; 2013): on one hand, availability of high precision, high quality $3 \mathrm{D}$ models is surely promoting development of integrated projects for documentation and digital communication of historic heritage; on the other hand, interesting research scenarios are disclosing as regards optimization of integration systems for digital 3D survey models in the processes of planning, execution and management of restoration and preservation projects in HBIM (Heritage Building Information Model) environments (Chiabrando et al., 2016).

In the field of architectural heritage, use of Terrestrial Laser Scanning (TLS) is to date well-established: its high precision in metric data collection, together with the limited time required for survey completion, makes TLS methodology an increasingly effective alternative to traditional direct surveying methods (Cardaci et al., 2011; Caroti et al., 2015; Caroti et al., 2012; Bevilacqua et al., 2016; Sperafico et al., 2015). The high metric strictness of TLS surveys, however, is not complemented by a matching quality as regards chromatic, and therefore material, information of building surfaces.

\footnotetext{
* Corresponding author
} 
Photogrammetry is surely more effective in meeting this requirement, although often at the expense of metric data precision. Recent price reductions of surveying devices (Amaro Mellado et al., 2012), together with the seeming intuitiveness of related software, have led to a strong increase of photogrammetric surveys processed with Structure from Motion (SfM) methodology. Achievement of virtual 3D models with photorealistic textures only requires shooting images from different viewpoints, whatever the scale or the orientation (Bolognesi et al., 2014; , Chiabrando et al., 2015).

Achievement of an effective model, however, requires careful monitoring in the model processing step (from image orientation to orthophotograph generation) so to check any output for accuracy and precision (Cipriani et al., 2013). Therefore, surveys aiming at providing strictness for both these aspects require integration of survey methodologies, where TLS is responsible for metric strictness and SfM applied to photogrammetry ensures chromatic fidelity.

This paper presents the results of the survey of St. Agatha Chapel, Pisa, carried out by integrating TLS and SfM methodologies, within a joint project in collaboration with Pisa Municipality aimed at the restoration and development of the monument. The architectural survey, together with the analysis of historic archival and bibliographical sources, is a basic tool for the historic appreciation of the monument, of its aesthetic and formal connotations, building techniques, degradation phenomena etc. The implemented methodology enabled to generate a set of 1:25 graphical documents providing metric reliability and quality. Besides, particular interest to the purposes of the present paper lies in the integration of the survey model with data from historic archival photographs, which provided useful elements for better comprehension of what is left of the inner wall paintings, currently unrecognizable due to advanced degradation.

\section{MATERIALS AND METHODS}

\subsection{Survey subject}

The Chapel of St. Agata (also called "in Badia") dedicated to Virgin Agata, martyred in Catania during the 3rd century, is located in Pisa on the back of the church of San Paolo a Ripa d'Arno, within the area next to the apse which was once part of the cloister of the monastery of St. Paolo (Figure 1).

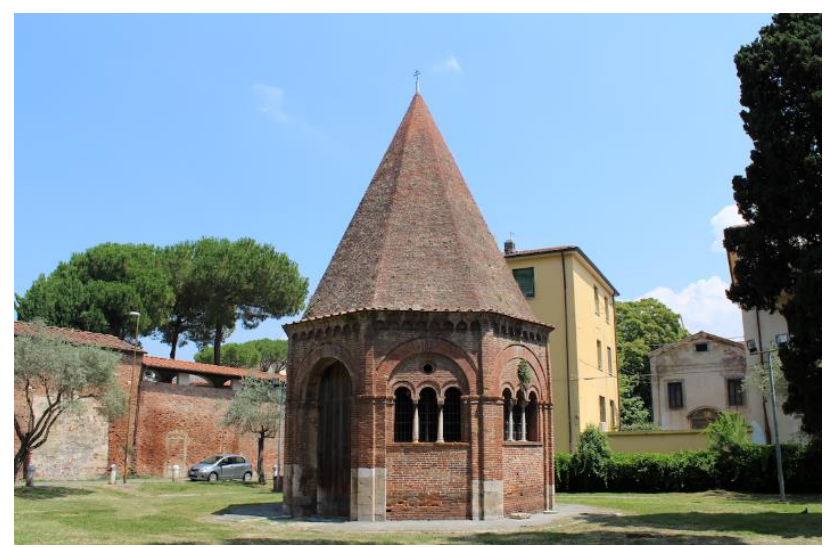

Figure 1. The Chapel of St. Agata - Pisa.

The date of construction is unknown, although it's traditionally considered to be 1063 or the subsequent years. The first written sources testifying the existence of the chapel are from the early $12^{\text {th }}$ century and originate from an epigraph located inside the adjacent church of San Paolo. The original use of the building is also unknown, as well as the name of its architect, although some historians suggest Diotisalvi as plausible (Paliaga \& Renzoni, 2005; Redi, 2000).

The chapel, almost entirely built of brick, has an octagonal plant topped by a spire. On four of the eight sides, we find a three-light window, while the entrance is located on the side facing the church of San Paolo; the remaining sides have no openings. Each side is approximately 3 meters long, the inner diameter is more or less 7 meters and the building is 14.50 meters high. Inside the chapel are located: an altar (mid-13th century), the tombstone of Prince Pietro Frangipane from Rome, who presumably died in 1367 , as well as stone fragments of cornices and friezes which were part of ancient decorations and were found during the latest restoration works.

The cloister which once encircled the chapel similarly dates to the beginning of the $12^{\text {th }}$ century and was later heavily modified over time; therefore, it is likely that the chapel has always been enclosed by buildings from its construction up to the 1950's. Its role as part of a larger complex explains why its fate has been strongly connected to the story of the adjacent buildings. During the bombing of the city of Pisa in 1943, the buildings surrounding the chapel were seriously damaged (Figure 2) and were demolished for safety reasons, so the chapel was finally made visible.

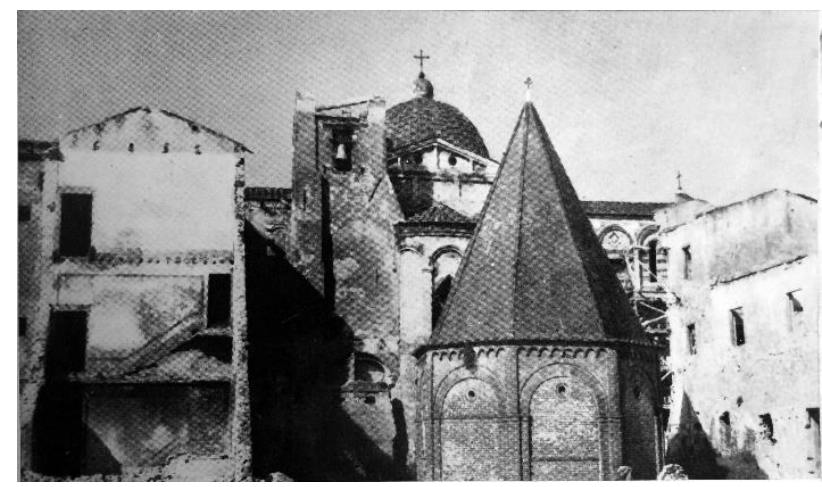

Figure 2. The chapel and the surrounding buildings during the bombing in 1943 (Nuti, 1957).

Since it hasn't been badly damaged by the bombing, the restoration began only in the mid 1950's and required a long time as it ended in the 1970's. During the restoration works, the chapel was brought to public attention for the discovery of some frescoes dated to the late $13^{\text {th }}$ - early $14^{\text {th }}$ century. A few years after the conclusion of the restoration works, the chapel was abandoned again.

\subsection{Surveying methodology}

In order to achieve a strict survey for both geometry and texture, an integrated TLS-photogrammetry survey methodology was chosen.

A preliminary survey of a network including 10 topography and 70 photogrammetry points, carried out by means of a Leica TPS1201+ total station, provided a common reference system for both methodologies and a set of Control Points (CPs) (Figure 3). Photogrammetry points were chosen based on easy detection, aiming at a millimeter-range point detection precision. To this purpose, decorations, friezes and corners provided workable details.

TLS survey relied upon a Leica C10 ScanStation with integrated camera, which performed scans on both the exterior and the interior of the chapel. The scans have subsequently been framed in the same reference system defined by the topographic survey. 


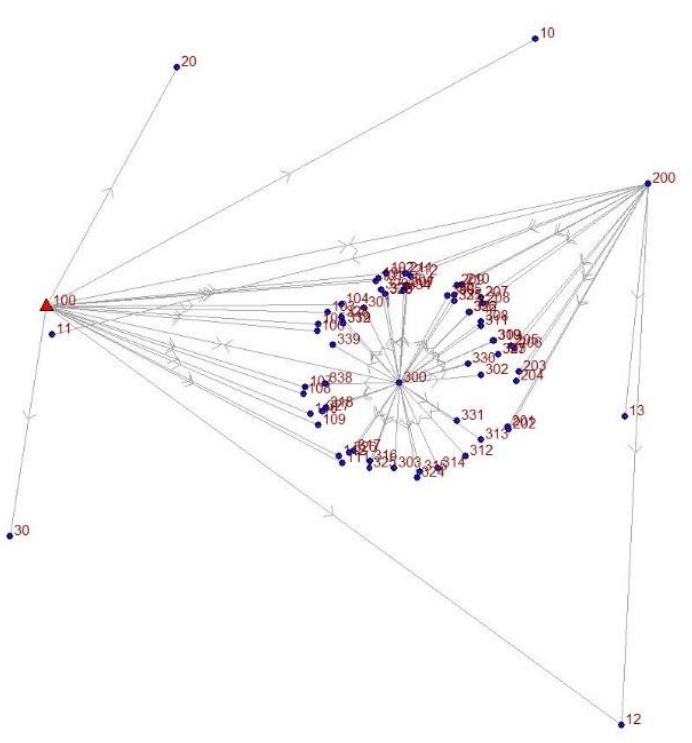

Figure 3. Plan view of photogrammetry and topography points.

Photogrammetry was carried out by means of a full-frame Nikon D700 digital camera, fitted with $20 \mathrm{~mm}$ and $50 \mathrm{~mm}$ lenses for interior and exterior shoots, respectively. Exterior shoots were taken circling around the chapel at a distance between $6 \mathrm{~m}$ and $10 \mathrm{~m}$, achieving a $70 \%$ overlap between consecutive shoots. The camera was mounted on a tripod, set at two different heights (about $1.3 \mathrm{~m}$ and $2.1 \mathrm{~m}$ ) for each shooting station; for each tripod height, shooting axis was both horizontal and slightly tilted, so to entirely frame the cusp of the chapel.

As regards the inside, the distance between camera and wall was in fact kept at about $6 \mathrm{~m}$, by placing the tripod close by any wall and shooting at the opposite wall. Tripod height was again set at two different levels (about $1.1 \mathrm{~m}$ and $2 \mathrm{~m}$ ), with $0^{\circ}$ and $30^{\circ}$ inclination with respect to the horizon. Besides, some photos have been shot with subvertical axis, so to completely frame the cusp interior always achieving a 70\% overlap between consecutive shoots.

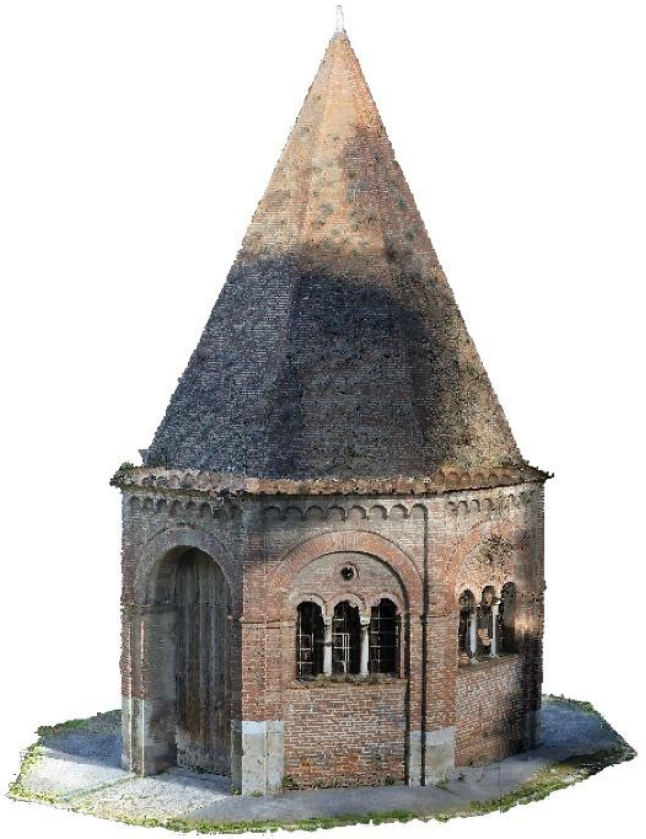

Figure 4. Texturized 3D model.
Thanks to the inserted tie points and Ground Control Points (GCPs), SfM software defined the internal orientation parameters of the camera and external orientation parameters in the same reference system in which the TLS model was registered. This allowed to subsequently import in the SfM software the surface model obtained by the TLS point cloud, and to texturize it with the photographs, upon their photogrammetric orientation (Figure $4)$.

\subsection{Methodology for model integration with archival images}

The 3D model was enhanced by integration with additional chromatic and material information. In fact, archival research found some images (Figures 5 and 6), dating back to the nineteen sixties, picturing the frescoes on the inside of the cusp in a better preservation state compared with the current decay.

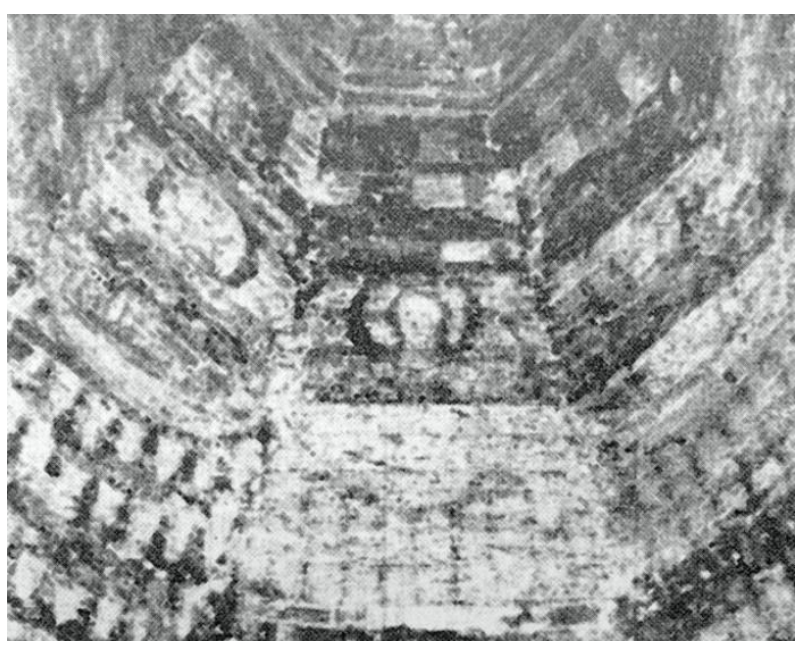

Figure 5. Wide viewing angle archival image (Burresi \& Caleca, 2003).

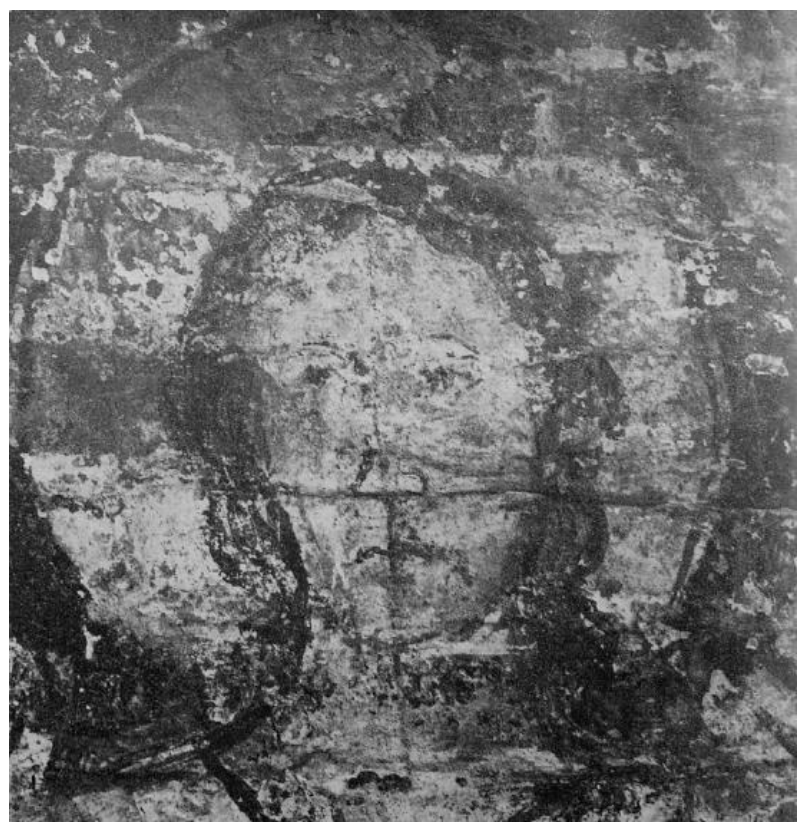

Figure 6. High-definition archival image (Comune di Pisa, 1965).

Two archival images, at different zoom levels, were chosen for integration purposes. The first one features a wider viewing angle and proved particularly useful as it allowed detection of 14 tie points (Figures 7 and 8) also used in the 2016 campaign to obtain 
the SfM model. Upon collimation of these tie points, aligning the historic image on the current image set yielded a standard deviation in the 1pixel range.

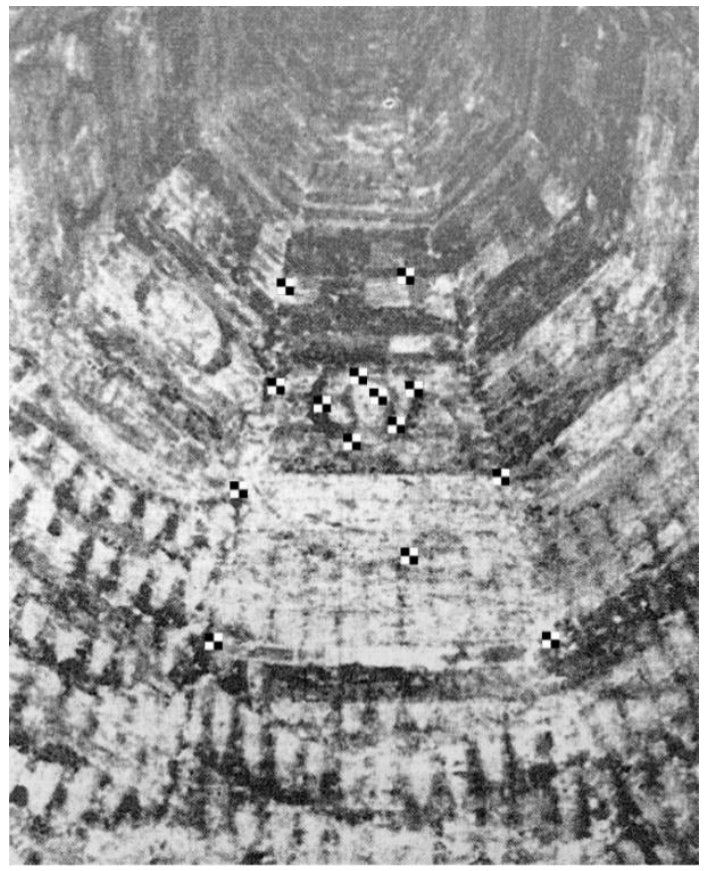

Figure 7. Tie points on wide viewing angle archival image.

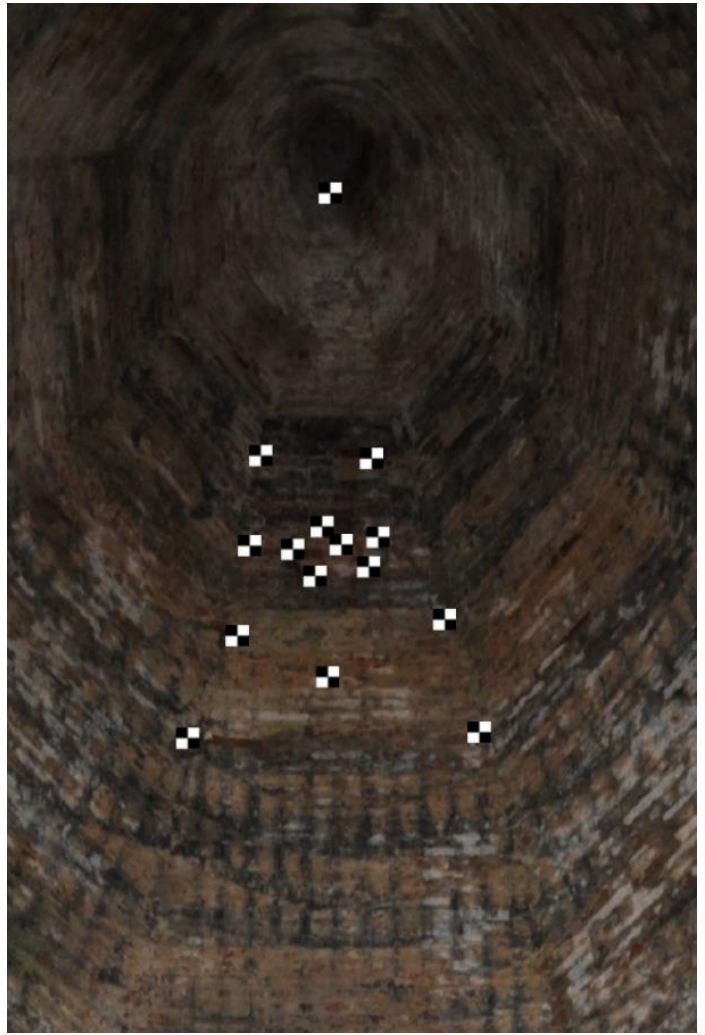

Figure 8. Tie points on 2016 surveyed image.

Orientation of the first historic image allowed to detect 6 additional tie points (Figure 9), visible in both the first image and the second archival image, which is a high-definition representation of the face of a human figure.

Aligning procedures on this image also yielded a standard deviation on the tie points in the 1pixel range.

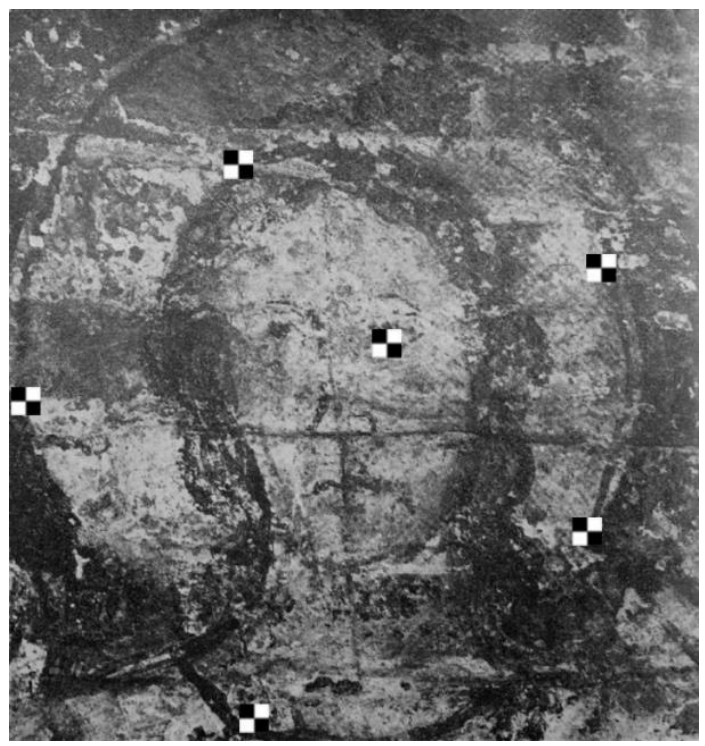

Figure 9. Tie points on high-definition archival image.

\section{RESULTS AND DISCUSSION}

Typical geomatics surveying and processing techniques permit to obtain a three-dimensional model. This model is characterised by geometric rigour and by a colour high-resolution description. The model, an actual replica of the surveyed object, can be explored in its three-dimensionality. In this way it's possible to analyze the architecture from otherwise not replicable in a direct inspection points of view.

From this model all classic 2D products for cognitive and planning phase are then achievable (Figures 10 and 11).

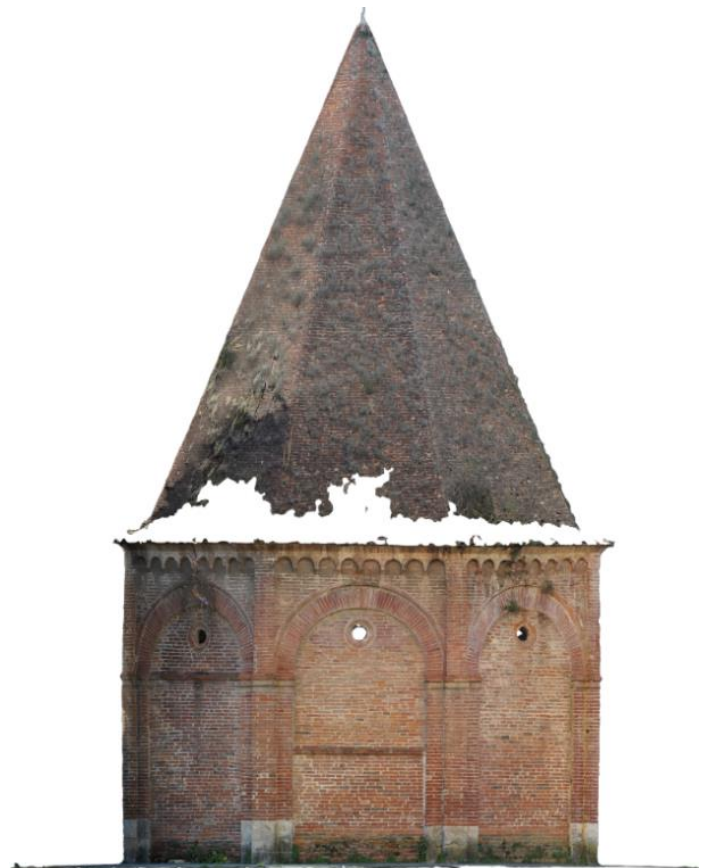

Figure 10. External orthophoto. 


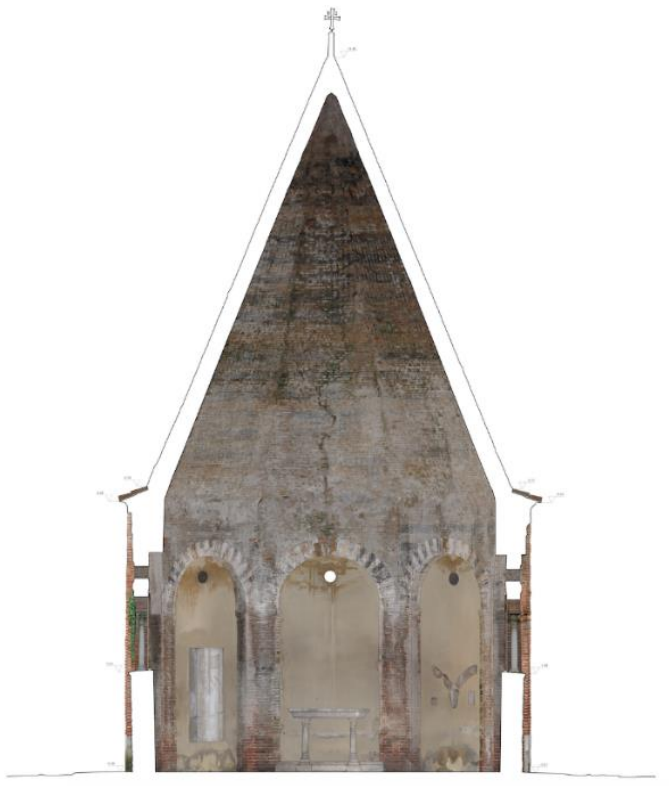

Figure 11. Example of the surey final drawings: vertical section (originale scale 1:25)

\subsection{Geomatic products for restoration purposes}

The integration of paintings survey with archival iconographic documents offers several advantages in the field of restoration. First, the choice of the methodology used for filling in the gaps or missing parts is strongly determined by the level of knowledge of the paintings and of their unaltered or less-deteriorated configuration, even if the restoration intervention must be recognizable and removable, respecting the Italian Restoration Chart of 1972. Second, referring information taken from archival photographic images to the 3D survey model can foster the development of projects for the digital communication and valorisation of a historical monument.

In the case of the Chapel of St. Agata, the integration of the survey model with archival images offers significant advantages in the restoration project of the wall paintings.

The restoration of mural paintings requires, as is well known, different interconnected operational phases, strongly influenced by the level of knowledge of the paintings and their degradation pathologies (Botticelli, 1992; Paolini \& Faldi, 1999; Rella \& Saccani, 2009).

The first phase consists in the preliminary investigations, aimed at assessing the characteristics of the painting, its constitutive materials and techniques, its state of conservation and the causes of its deterioration. In this phase, the historical-critical analysis plays a fundamental role for understanding the origin of the painting and any maintenance, alteration or restoration occurred over time. For this purpose, stratigraphic and cleaning tests can be useful for analysing the status of the pictorial surface and its stratigraphy. Specific diagnostic tests, performed in laboratory on small samples or in situ, may finally provide meaningful information for understanding the physic-chemical characteristics of the painting construction materials.

The second phase involves the safeguarding of the parts at risk of detachment, such as fastening techniques with protective facings or consolidations with localized injections or brush application of permanent natural or synthetic adhesives.

The third phase includes all the operation of preparation to the clean-up phase, such as the removal of incoherent deposits by brushing or suction of dust and residues, up to the mechanical precision removal of concretions, foreign bodies, cementitious layers and superstructures, as well as the elimination of any weeds with herbicide products and the removal of the pathogenic microflora with biocidal products.

The fourth phase consists in the operations aimed at cleaning the painting from all the extraneous pathogenic substances (such as surface deposits, encrustations, discolorations, stains, biodeteriogens, etc.) with wet (vaporized sprayed or atomized water, compresses with chemical reagents, special clays) or dried treatments (Wishab sponges or thermocautery).

The fifth phase provides all the consolidation operations, carried out by means of spray application of consolidating products or by brush, aimed at restoring the cohesion of the constructive layers and at limiting the disintegration phenomena of the plaster or the delamination or exfoliation of the pictorial film. Closely related to the latter, the grouting of gaps, faults and fissures, up to the refurbishing of plaster fallen portions, with the aim of restoring the structural continuity and making the surface more stable and readable.

The last phase is the pictorial reintegration of gaps and abrasions of the pictorial layer, in order to achieve a critical restoration of the pictorial text. Several methodologies can be used: the restoration of the gaps with neutral backgrounds, chromatic selection, chromatic abstraction or by striped weaves of colour ("rigatino"), up to the imitative undertone reintegration. In any cases, though the recognisability and the reversibility of the reintegration must be guaranteed, the level of knowledge of the painting plays a fundamental role, as the method of reintegration is strictly determined by the level of 'confidence' that the restorer has in foreshadowing the painting in its original unaltered state. Therefore, in the case of the Chapel of St. Agata, it is clear that the 3D model integration with the archival photos that describe the painting in a state of minor decay, provides valuable information not only for the historical and formal analysis of the painting, but also for the evaluation of which method of intervention can be used in the phase of reintegration.

The survey drawings, with the paintings reconstruction in scale 1:25 (Figure 12), represent therefore a very useful tool which allows to choose more mimetic methods of reintegration, such as the undertone imitative reintegration.

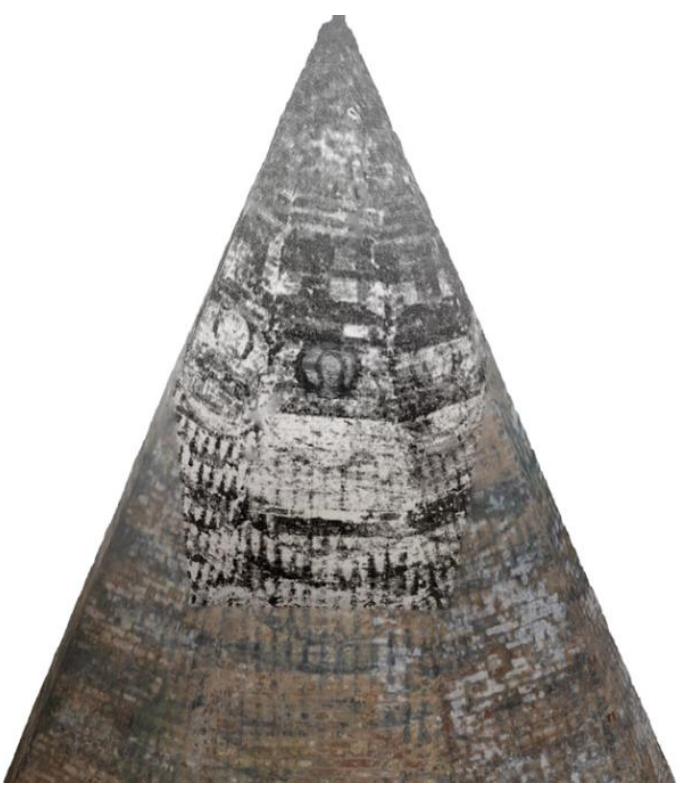

Figure 12. High-resolution image orientation and projection on the 3D model.

\section{CONCLUSIONS}

The modern survey technologies offer many advantages in the field of restoration and interesting perspective of research for the 
valorisation and communication of the historical architectural heritage.

In and of itself, the possibility of navigating into a textured 3D model offers points of view - and analysis - of the monument, from which it could be possible to seize formal and constructive aspects otherwise not visible on site. Furthermore, in the case of the Chapel of St. Agata, the possibility of referring to the 3D survey model some historical photos that describe the state of the wall paintings in a less deteriorated - and therefore more readable - state, allows an in-depth knowledge of the paintings and therefore can guide the restorer in choosing the most suitable method of pictorial reintegration.

Moreover, the opportunity to report information taken from archival iconographic sources to the 3D model allows the development of projects for the digital communication and valorisation of monuments.

\section{ACKNOWLEDGEMENTS}

Thanks are due to Andrea Bedini and Jessica Micheloni for technical support in the surveying phase.

\section{REFERENCES}

Amaro Mellado, J. L., Aguilar Alejandre, M., Barrera Vera, J. A., 2012. "Nuevas tecnologías y métodos tradicionales en el levantamiento de patrimonio arquitectónico" in Proceedings of the XI Congreso Internacional de Expresión Gráfica Aplicada a la Edificación, Universidad Politécnica de Valencia, Valencia, Spain, 29 November-1 December 2012; pp. 575-582.

Bevilacqua, M. G., Caroti, G., Zaragoza, I.M.-E., Piemonte, A., 2016. Frescoed vaults: Accuracy controlled simplified methodology for planar development of three-dimensional textured models. Remote Sensing, 8 (3), art. no. 239, DOI: $10.3390 /$ rs 8030239 .

Bolognesi, M., Furini, A., Russo, V., Pellegrinelli, A., Russo, P., 2014. Accuracy of cultural heritage 3D models by RPAS and terrestrial, in The International Archives of the Photogrammetry, Remote Sensing and Spatial Information Sciences, Volume XL5, ISPRS Technical Commission V Symposium, pp. 113-119, DOI:10.5194/isprsarchives-XL-5-113-2014.

Botticelli, G., 1992. Metodologia e Restauro delle Pitture Murali. Edizioni Centro Di, Firenze.

Burresi, M. \& Caleca, A., 2003. Affreschi medievali a Pisa, Pacini Editore, Pisa.

Cardaci, A., Mirabella Roberti, A., Versaci, A., 2011. From the continuos to the discrete model: a laser scanning application to conservation projects, in The International Archives of the Photogrammetry, Remote Sensing and Spatial Information Sciences, Volume XXXVIII-5/W16, ISPRS Trento 2011 Workshop, 2-4 March 2011, Trento, Italy.

Caroti, G., Franconi, A., Piemonte, A., 2012. Metodologia di elaborazione dati laser scanner per la generazione di modelli utili al calcolo strutturale, in Proceedings of 16 a Conferenza Nazionale ASITA, pp.383-390, ISBN 978-88-903132-7-1.

Caroti, G., Martínez-Espejo Zaragoza, I., Piemonte, A., 2015a. Range and image based modelling: A way for frescoed vault texturing optimization, in The International Archives of the Photogrammetry, Remote Sensing and Spatial Information
Sciences, 40 (5W4), pp. 285-290, DOI: 10.5194/isprsarchivesXL-5-W4-285-2015.

Caroti, G., Martínez-Espejo Zaragoza, I., Piemonte, A., 2015b. Accuracy assessment in structure from motion 3D reconstruction from UAV-born images: The influence of the data processing methods, in The International Archives of the Photogrammetry, Remote Sensing and Spatial Information Sciences, 40 (1W4), pp. 103-109, DOI: 10.5194/isprsarchives-XL-1-W4-103-2015.

Chiabrando, F., Donadio, E., Rinaudo F., 2015. SfM for orthophoto generation: awinning approach for cultural heritage knowledge, in The International Archives of the Photogrammetry, Remote Sensing and Spatial Information Sciences, Volume XL-5/W7, pp. 91-98, doi:10.5194/isprsarchives-XL-5-W7-91-2015.

Chiabrando, F., Sammartano, G., Spanò, A., 2016. Historical buildings models and their handling via $3 \mathrm{~d}$ survey: from points clouds to user-oriented HBIM, in The International Archives of the Photogrammetry, Remote Sensing and Spatial Information Sciences, Vol.XLI-B5, pp.633-640. DOI:10.5194/isprsarchivesXLI-B5-633-2016.

Cipriani, L., Fantini, F., Bertacchi, S., 2013. Criteri di indagine degli spazi voltati nell'ambito dell'architettura storica $\mathrm{e}$ in archeologia, in SCIentific RESearch and Information Technology - SCIRES-IT, Vol 3, Issue 2 (2013), 101-134, e-ISSN 2239-4303, DOI 10.2423/i22394303v3n2p101.

Comune di Pisa, 1965. Editoriale, Interessanti scoperte nell'oratorio di S. Agata, in Rassegna periodica di informazioni, Anno I, n 2 marzo 1965, p. 38, Tipografia Comunale, Pisa.

Costantino, D., Angelini, M.G., Baiocchi, V., 2016. Integrated surveying for the archaeological documentation of a neolithic site, in Geographia Technica, Volume 11, Issue 2, pp. 39-49, DOI: 10.21163/GT_2016.112.04.

Dominici, D., Rosciano, E., Alicandro, M., Elaiopoulos, M., Trigliozzi, S., Massimi, V., 2013. Cultural heritage documentation using geomatic techniques: Case study: San Basilio's monastery, L'Aquila, in Proceedings of the DigitalHeritage 2013 - Federating the 19th Int'l VSMM, 10th Eurographics GCH, and 2nd UNESCO Memory of the World Conferences, Plus Special Sessions fromCAA, Arqueologica 2.0 et al., Volume 1, pp. 211-214, DOI 10.1109/DigitalHeritage.2013.6743735.

D'Urso, M.G., Marino, C.L., Rotondi, A., 2014. On 3D dimension: Study cases for archaeological sites, in The International Archives of the Photogrammetry, Remote Sensing and Spatial Information Sciences, Volume 40, Issue 6, pp.13-18, DOI: 10.5194/isprsarchives-XL-6-13-2014.

Fregonese, L., Fassi, F., Achille, C., Adami, A., Ackermann, S., Nobile, A., Giampaola, D., Carsana, V., 2016. 3D survey technologies: Investigations on accuracy and usability in archaeology. The case study of the new "Municipio" underground station in Naples, in Acta IMEKO, Volume 5, Issue 2, pp. 55-63, DOI: 10.21014/acta_imeko.v5i2.342.

Lo Brutto, M., Spera, M.G., 2011. Image-based and range-based 3D modelling of archaeological cultural heritage: The telamon of the temple of Olympian Zeus in Agrigento (Italy), in The International Archives of the Photogrammetry, Remote Sensing 
and Spatial Information Science, Volume 38, (5W16), pp. 515522 .

Nuti, G., 1957. Esperienze di restauro - La chiesa di San Paolo a Ripa d'Arno in Pisa. Architettura e Restauro: esempi di restauro eseguiti nel dopoguerra, Milano, pp. 147-149.

Paliaga, F. \& Renzoni, S., 2005. Chiese di Pisa. Guida alla conoscenza del patrimonio artistico, ETS, Pisa, p. 13.

Paolini, C. \& Faldi, M., 1999. Glossario delle tecniche pittoriche e del restauro. Firenze: edizioni Palazzo Spinelli.

Redi, F., 2000. Pisa: la città, le chiese, le case, le cose. Guida storico-artistica, Silvana Editoriale, Milano, pp. 85-86.

Rella, L. \& Saccani, L., 2009. Schede Tecniche per il restauratore di dipinti murali, su tela e su tavola, Hoepli, Milano.

Spreafico, M.C., Perotti, L., Cervi, F., Bacenetti, M., Bitelli, G., Girelli, V.A., Mandanici, E., Tini, M.A., Borgatti, L., 2015. Terrestrial Remote Sensing techniques to complement conventional geomechanical surveys for the assessment of landslide hazard: The San Leo case study (Italy), in European Journal of Remote Sensing, Volume 48, pp. 639-660, DOI: 10.5721/EuJRS20154835.

Tucci, G., Bonora, V., 2015. Geomatics and management of atrisk cultural heritage, in Rendiconti Lincei, Volume 26, pp. 105114, DOI: 10.1007/s12210-015-0427-0. 